УДК 582.998.2:547.587

\title{
СРАВНИТЕЛЬНОЕ ИЗУЧЕНИЕ АНТИОКСИДАНТНЫХ СВОЙСТВ ЭКСТРАКТОВ РАЗЛИЧНЫХ ВИДОВ АЛОЕ
}

\author{
(C) Н.Н. Сажина ${ }^{I}$, П.В. Лапиин ${ }^{2}$, Н.В. Загоскина ${ }^{2}$, В.М. Мисин ${ }^{I}$ \\ ${ }^{1}$ Институт биохимической фризики им Н.М. Эмануэля РАН, ул. Косыгина, 4, \\ Москва, 119334 (Россия), e-mail: Natnik48s@yandex.ru \\ ${ }^{2}$ Институт фозиологии растений им. К.А. Тимирязева РАH, \\ ул. Ботаническая, 35, Москва, 127276 (Россия)
}

В настоящее время представляет интерес изучить биологическую, в том числе и антиоксидантную, активность различных лекарственных растений с целью поиска среди них наиболее активных источников биологически активных соединений. И в этом плане большой интерес вызывают некоторые суккулентные растения рода Алое, препараты из которых широко применяют в отечественной медицине. В представленной работе проведен сравнительный анализ результатов измерений антиоксидантной активности (AOA) спиртовых экстрактов листьев 15 различных видов Алое амперометрическим и хемилюминесцентным методами. Отмечена значительная разница между значениями АОА, полученными этими методами для некоторых видов Алое, и дается объяснение этому факту. Среди изученных образцов выявлен наиболее активный с точки зрения AOA представитель рода Aloe - A. pillansii, экстракты листьев которого имеют высокие значения АОА, полученные обоими методами. Достаточно высокую антиоксидантную активность, кроме A. pillansii и A. arborescens, проявили также A. broomii и A. spinosissima. Выявленные новые виды Алое могут оказаться не менее перспективными источниками биологически активных соединений, чем традиционно используемые A. Arborescens и A.vera.

Ключевые слова: антиоксиданты, амперометрический и хемилюминесцентный методы, фенольные соединения, Aloe.

\section{Введение}

Одной из актуальных задач современной фармацевтической науки является создание новых лекарственных средств на основе растительного сырья. И в этом плане большой интерес вызывают некоторые суккулентные растения рода Алое и Каланхое, препараты из которых широко применяют в отечественной медицине [1]. При проведении скрининга у 34 представителей рода Каланхое по оценке антиоксидантной активности (AОА) соков из их листьев были выявлены два наиболее активных с этой точки зрения вида [2]. Они могут оказаться более перспективными продуцентами биологически активных соединений по сравнению с использующимися в настоящее время видами Каланхое. Целесообразно провести аналогичный скрининг и среди представителей рода Алое. Современные оперативные методы исследования антиоксидантных свойств позволяют на более высоком уровне изучить их и осмыслить лекарственную ценность того или иного растения. Одним из таких методов является разработанный Я.И. Яшиным с сотруд-

Сажина Наталья Николаевна - кандидат физикоматематических наук, старший научный сотрудник, тел. (495) 939-74-18, e-mail: natnik48s@yandex.ru Лапиин Петр Владимирович - кандидат биологических наук, научный сотрудник, тел. (499) 977-94-33, e-mail: p.lapshin@mail.ru

Загоскина Нататья Викторовна - доктор биологических наук, ведущий научный сотрудник, тел. (499) 977-94-33, e-mail: nzagoskina@ mail.ru Мисин Вячеслав Михайлович - доктор химических наук, заведующий лабораторией комплексной оценки антиоксидантов, тел. (495) 939-74-09, e-mail:misin@sky.chph.ras.ru никами амперометрический метод [3], который авторы использовали в настоящей работе. В монографии разработчиков [4] и статье [5] приведен широкий обзор работ, проведенных ими с использованием данного метода и ВЭЖХ для различных биологических объектов, включая и экстракты лекарственных трав, и сравнение с другими методами. Яшиным и его учениками создан банк данных [6] по содержанию антиоксидантов в продуктах питания и напитках. Однако скрининг АОА экстрактов раз-

\footnotetext{
*Автор, с которым следует вести переписку.
} 
личных видов Алое не проводился. Поэтому в настоящей работе авторы провели его с использованием амперометрического и, кроме того, достаточно оперативного хемилюминесцентного методов.

Род Алое включает около 270 видов суккулентных растений, для которых характерно формирование «сочных» водозапасающих листьев, собранных в розетку [7]. Родина этих растений - Южная Африка, а также остров Мадагаскар. В основном Алое используются как декоративные виды, но некоторые из них применяются и в лечебных целях. Это связано с тем, что в их листьях содержится много биологическиактивных веществ, в том числе и фенольной природы $[1,7]$. Именно фенольные соединения и обусловливают АОА того или иного вида растения, то есть способность его компонент ингибировать окислительные свободнорадикальные процессы $[8,9]$. Самыми известными и популярными видами рода Алое являются: Алое древовидное (Aloe arborescens Mill.) и Алоэ настоящее (Aloe vera (L.) Burm.f.). Эти виды давно используются как ценные лекарственные растения в фармацевтике для производства препаратов с широким спектром медицинского назначения [1]. Авторы работ [10-14] современными спектрофотометрическими и ВЭЖХ методами исследовали химический состав и количественное содержание биологически активных соединений в соке и экстрактах Aloe arborescens. Определена и антирадикальная активность этих экстрактов с применением ДФПГ и других методов [11]. В последние годы большой интерес вызывает Aloe vera, компоненты которого также проявляют антирадикальную и противомикробную активность [15]. При изучении соединений Aloe barbadensis был отмечен их ингибирующий эффект на фосфодиэстеразу [16]. В исследованиях упоминаются и другие представители рода Алое. Например, для Aloe ferox, используемого в качестве общего профилактического и противоопухолевого средства в народной медицине, показано антиоксидантное, противомикробное, противовоспалительное и противомалярийное действие [17]. Этот вид Алое приобрел популярность и в качестве ингредиента в косметических композициях и пищевых добавках. Выделенные из корней Aloe secundiflora такие фенольные соединения, как нафтохиноны, показали антибактериальную активность [18]. Южноафриканский вид Aloe barberae тоже проявляет антибактериальное, фунгицидное и противовоспалительное действие [19]. Aloe ferox, Aloe mitriformis, Aloe saponaria продемонстрировали высокую противогрибковую активность, что может быть альтернативой A. vera для различных практических применений [20]. Упоминается также вид Алоэ sinkatana [21]. Все эти данные свидетельствуют о разноообразной активности различных представителей рода Алое. Что касается сравнительных характеристик антиоксидантных свойств разных видов Алое, то результатов таких целенаправленных научных исследований в литературе нет.

Цель настоящей работы - определение АОА экстрактов 15 видов Алое амперометрическим и хемилюминесцентным методами и выявление среди них потенциальных источников биологически активных соединений.

\section{Экспериментальная часть}

Объектами исследования являлись пятнадцать представителей рода Алое, выращиваемых в коллекции суккулентов в Институте физиологии растений им. К.А. Тимирязева РАН в Москве в условиях оранжереи при естественном освещении. Молодые (не достигшие полного размера) и взрослые (годовалые) листья были срезаны с растений в июле 2014 г. Свежий материал подвергали экстракции 70\%-ным этанолом для извлечения фенольных соединений [22]. Отдельно для Алое древовидного были использованы и другие способы извлечения: водой, $40 \%$-ным и $96 \%$-ным этанолом (для сравнения степени экстракции биологически активных веществ из листьев).

Измерения АОА исследуемых образцов проводились электрохимическим (амперометрическим) и хемилюминесцентным (ХЛ) методами.

Сущность амперометрического метода, реализованного в приборе «Цвет-Яуза-01-АА», заключается в измерении электрического тока, возникающего при электрохимическом окислении исследуемого вещества на поверхности рабочего электрода с потенциалом на стеклоуглеродном аноде $+1,3$ В [23]. При таких значениях потенциала происходит окисление многих природных фенольных (R-OH), тиоловых (R-SH) и других соединений, протекающее по схеме $\mathrm{R}-\mathrm{OH} \rightarrow \mathrm{R}-\mathrm{O}^{*}+\mathrm{e}^{-}+\mathrm{H}^{+}$, и может быть использовано как модельное при измерении активности поглощения свободных радикалов [24]. Захват свободных радикалов осуществляется в соответствии с реакцией $\mathrm{R}-\mathrm{OH} \rightarrow \mathrm{R}-\mathrm{O}^{*}+\mathrm{H}^{*}$. В этом случае способность к захвату свободных радикалов фенольными соединениями может измеряться величиной их окисляемости на рабочем электроде амперометрической ячейки. При прохождении пробы через ячейку регистрируется ток электро- 
химического окисления АО, который сравнивается с током, полученным в тех же условиях для эталонного образца с известной концентрацией (тролокса). Суммарная АОА образцов определяется по калибровочной зависимости окисляемости тролокса (интеграл по времени кривой окисления) от его концентрации в мМ тролокса. Метрологические особенности определения АОА этим методом изложены в [25]. Погрешность измерения АОА с учетом воспроизводимости результатов составила менее $10 \%$.

В хемилюминесцентном (ХЛ) методе определения АОА использовалась схема окисления системы «гемоглобин $(\mathrm{Hb})-\left(\mathrm{H}_{2} \mathrm{O}_{2}\right)$ - люминол», в которой образование радикалов-инициаторов происходит при взаимодействии $\mathrm{Hb}$ и $\mathrm{H}_{2} \mathrm{O}_{2}$, а люминол играет роль хемилюминогенного субстрата окисления [26]. Взаимодействие $\mathrm{H}_{2} \mathrm{O}_{2}$ c $\mathrm{Hb}$, с одной стороны, сопровождается разрушением гема и выходом из него ионов железа, которые участвуют в образовании $\mathrm{OH}^{\bullet}$, с другой стороны, приводит к возникновению радикалов феррил $\mathrm{Hb}\left(\mathrm{Hb}\left({ }^{\bullet+}\right)-\mathrm{Fe}^{4+}=\mathrm{O}\right)$. Указанные радикалы-инициаторы вызывают одноэлектронное окисление люминола. $\mathrm{B}$ процессе его окисления образуется $\mathrm{L}^{\bullet-}$-радикал люминола, супероксид-радикал $\mathrm{O}_{2}^{\bullet-}$, эндопероксид люминола $\mathrm{LO}_{2}{ }^{2-}$ и 3-аминофталат дианион $\left(\mathrm{AP}^{2-}\right)^{*}$, при переходе которого в основное состояние высвечивается квант света. Отличительной особенностью этой окислительной системы является то, что образующиеся в ней радикалы могут инициировать свободнорадикальные реакции in vivo. Подробная методика измерений приведена в [26]. Для реализации данного метода в настоящей работе был использован прибор «Lum5373». В ячейку прибора добавлялись 50 мкл $\mathrm{Hb}$ (15 мкM, «Sigma»), 100 мкл люминола (1 мМ, «Диаэм»), 10 мкл $\mathrm{H}_{2} \mathrm{O}_{2}$ (13 мМ, «Химмед»), 2,35 мл буферного раствора и разные дозы исследуемых проб (от 0,1 до 30 мкл). Латентный период ( $\left.\mathrm{t}-\mathrm{t}_{0}\right)$ вычислялся от времени введения в ХЛ ячейку $\mathrm{H}_{2} \mathrm{O}_{2}$ до точки пересечения касательной в точке перегиба ХЛ кривой с временной осью [26]. $\mathrm{t}_{0}$-латентный период в отсутствии пробы. Калибровка осуществлялась по зависимости латентного периода от концентрации тролокса. АOA исследуемых образцов определялась по калибровочной прямой, в мМ тролокса. Погрешность измерения АОА данным методом составила не более $15 \%$. Статистическую обработку результатов проводили при использовании стандартных алгоритмов программ MS Excel. Для сравнения результатов для всех видов алое, полученных двумя разными методами, использовался корреляционный метод Пирсона и вычислялся коэффициент корреляции $\mathrm{r}$ и уровень значимости. Достоверность различия величин для каждого вида считали по t-критерию Стьюдента. Использовали 95\% доверительную вероятность, а достоверными считали различия при $\mathrm{p} \leq 0,05 »[27]$.

\section{Результаты и обсуждение}

В первую очередь мы использовали амперометрический метод для определения АОА в этанольных экстрактах листьев разного возраста нескольких видов Алое (рис. 1). Как следует из полученных данных, активности молодых и взрослых листьев различаются, что наиболее ярко проявляется у Aloe arborescens. Так, у Aloe mitriformis и H. coarctata более высокие значение АОА отмечены в молодых листьях, тогда как у Aloe arborescens - во взрослых. В то же время у Aloe vera и Aloe rauhii уровень активности не зависел от возраста листьев. Исходя из этих данных, для последующего скрининга АОА по возможности были использованы взрослые листья Алое примерно годовалого возраста.

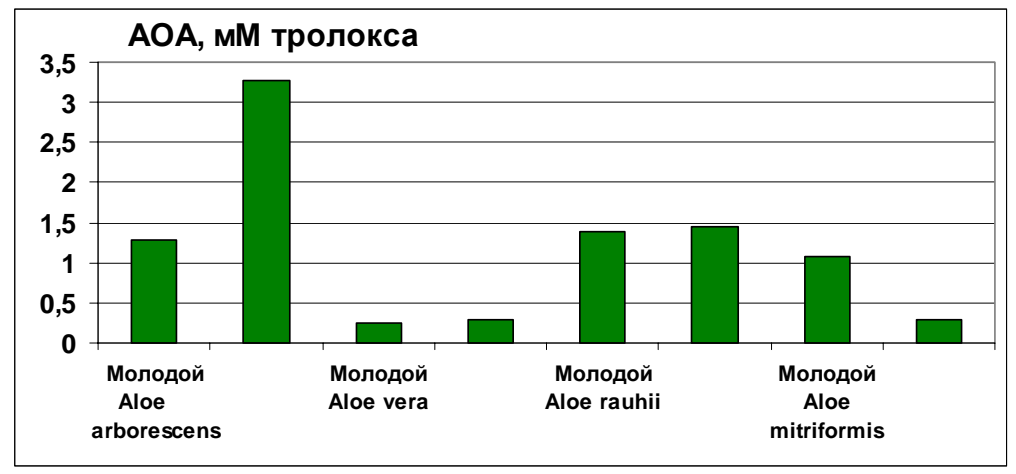

Рис. 1. АОА этанольных экстрактов молодых и взрослых листьев нескольких видов Алое, измеренная амперометрическим методом (1,5 мл 70\%-ного этанола, 0,25 г свежего растения) 
В таблице 1 представлены результаты измерения АОА различных экстрактов двумя методами. Для AOA указаны среднеквадратичные отклонения от средних значений, полученные для четырех измерений в течение двух дней для амперометрии (СКО при повторах для одного измерения $\leq 5 \%)$ и трех повторных измерений для хемилюминесценции.

Для A. striata (№10) указаны два образца: спиртовый экстракт и сок. Для Aloe arborescens (№1) придставлены еще 4 образца (№1a - 1б) для разных экстрактов. Результаты свидетельствуют, что максимальная степень экстракции активных веществ, определенная по АОА в обоих методах, достигается 70\%-ным и 96\%-ным этанолом, поэтому сравнительный анализ АОА для 15 видов алое, представленных в таблице 1 , был проведен для 70\%-ных спиртовых экстрактов. Самые низкие значения АОА оказались у A. vera (№2), самые высокие - у A. pillansii (№5). У разных видов наблюдается сильное различие в значениях АОА, измеренных двумя методами (в 5-10 раз), поэтому корреляция результатов по всем 15 образцам получилась невысокая ( $\mathrm{r}=0,704$, с достоверностью аппроксимации $\mathrm{R}^{2}=0,496$ и уровнем значимости для одностороннего критерия $\leq 0,001)$. В случае АОА для соков каланхое подобного не наблюдалось [2]. Это может свидетельствовать о значительном различии в составе исследованных видов Алое.

На рисунке 2 приведены кинетические хемилюминесцентные кривые, характерные для отдельных видов Алое. Для сравнения приведена ХЛ-грамма для 1 мкл тролокса (кривая 2), на которой четко выражен латентный период $\left(\mathrm{t}-\mathrm{t}_{0}\right)$ и практически не уменьшается амплитуда ХЛ. Такие ХЛ-граммы характерны для многих низкомолекулярных фенольных соединений: аскорбиновой, галловой кислот, катехинов, кверцетина и пр. Уменьшение амплитуды ХЛ, как правило, связано с присутствием в образцах белковых и ферментных структур [26]. Для кинетических кривых некоторых экстрактов Алое (кривые 2, 6, 7) наблюдается достаточно выраженный латентный период и понижение амплитуды ХЛ, зависящее от дозы экстракта. Такое поведение ХЛ-кривых наблюдается у образцов №№3, 5, 6, 9, 10, 13, 14, 15 и свидетельствует о достаточно высоком содержании в них фенольных антиоксидантов, что подтверждается их высокой окисляемостью, регистрируемой амперометрией (табл. 1). По-разному ведут себя экстракт и сок A. striata (№10 кривые 6 и 7). Сок дает больший латентный период, чем спиртовый экстракт, что связано, вероятно, с различием ингибирования окисления люминола компонентами сока и спиртового экстракта. Специально проверенное влияние спирта на параметры ХЛ показало, что в используемых концентрациях это влияние практически не проявляется.

Самым ярким представителем рассмотренной группы экстрактов Алое является образец №5 (рис. 3). Оба метода для него демонстрируют высокие значения АОА. ХЛ тушится практически полностью уже при малой дозе экстракта (1 мкл) и за счет увеличения латентного периода, что подтверждается высоким значением АОА по амперометрии, и за счет уменьшения амплитуды ХЛ, что свидетельствует о наличии в листьях этого вида каких-либо белков и ферментов.

Таблица 1. Антиоксидантная активность (АОА) образцов экстрактов, измеренная двумя методами

\begin{tabular}{|c|c|c|c|c|c|}
\hline $\begin{array}{l}\text { № } \\
\text { обр. }\end{array}$ & $\begin{array}{l}\text { Название } \\
\text { растения }\end{array}$ & Вид экстракта & $\begin{array}{c}\text { АОА, мМ тролокса, } \\
\text { амперометрия }\end{array}$ & $\begin{array}{l}\text { АОА, мМ тролокса, } \\
\text { хемилюминесц. }\end{array}$ & $\mathrm{p}$ \\
\hline 1 & A. arborescens & 70\%-ный этанол 2 мл, 1 г алое & $3,68 \pm 0,26$ & $0,44 \pm 0,12$ & 0,0001 \\
\hline 2 & A. vera & - & $0,24 \pm 0,02$ & $0,04 \pm 0,01$ & 0,001 \\
\hline 3 & A. spinosissima & - & $2,16 \pm 0,11$ & $1,28 \pm 0,15$ & 0,002 \\
\hline 4 & A. delaeti & - & $0,88 \pm 0,07$ & $0,19 \pm 0,08$ & 0,005 \\
\hline 5 & A. pillansii & - & $5,16 \pm 0,23$ & $4,55 \pm 0,32$ & 0,025 \\
\hline 6 & A. rauhii hybr. & - & $2,12 \pm 0,11$ & $0,29 \pm 0,08$ & 0,0001 \\
\hline 7 & A. jucunda & - & $0,78 \pm 0,05$ & $0,12 \pm 0,02$ & 0,003 \\
\hline 8 & A. squarrosa & - & $1,73 \pm 0,11$ & $0,65 \pm 0,05$ & 0,005 \\
\hline 9 & A. variegata & - & $0,85 \pm 0,03$ & $0,43 \pm 0,09$ & 0,001 \\
\hline $10 \mathrm{a}$ & A. striata & 70\%-ный этанол 2 мл, 1 г алое & $1,08 \pm 0,04$ & $0,60 \pm 0,09$ & 0,002 \\
\hline 106 & A. striata & сок & $1,05 \pm 0,04$ & $1,03 \pm 0,08$ & 0,323 \\
\hline 11 & A. dorotheae & 70\%-ный этанол 2 мл, 1 г алое & $0,51 \pm 0,02$ & $0,19 \pm 0,02$ & 0,002 \\
\hline 12 & A. hemmingii & - & $0,47 \pm 0,04$ & $0,07 \pm 0,02$ & 0,0001 \\
\hline 13 & A. broomii & - & $1,68 \pm 0,15$ & $2,65 \pm 0,12$ & 0,005 \\
\hline 14 & A. plicatilis & - & $0,92 \pm 0,04$ & $0,75 \pm 0,15$ & 0,051 \\
\hline 15 & A. brevifolia & - & $0,49 \pm 0,03$ & $0,40 \pm 0,12$ & 0,152 \\
\hline 1a & & вода 1 мл, 0,5 г & $2,26 \pm 0,06$ & $0,13 \pm 0,01$ & 0,0001 \\
\hline 16 & & 40\%-ный этанол 1 мл & $2,78 \pm 0,12$ & $0,25 \pm 0,03$ & 0,0001 \\
\hline $1 \mathrm{~B}$ & A. arborescens & 70\%-ный этанол 1 мл & $2,99 \pm 0,12$ & $0,30 \pm 0,03$ & 0,0001 \\
\hline $1 \Gamma$ & & 96\%-ный этанол 1 мл & $3,28 \pm 0,14$ & $0,29 \pm 0,03$ & 0,0001 \\
\hline
\end{tabular}




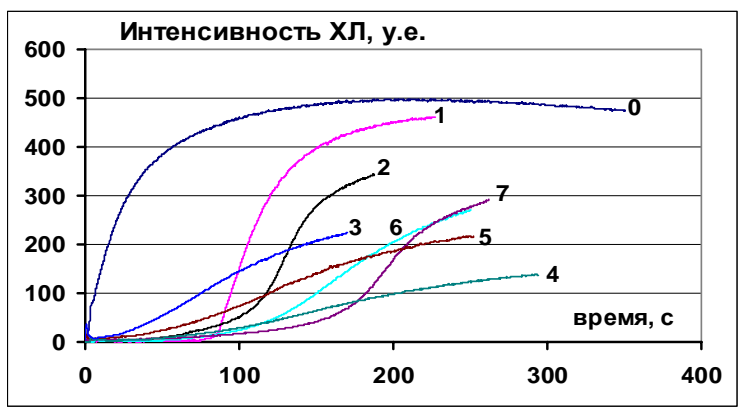

Рис. 2. Зависимость интенсивности ХЛ от времени при добавлении в окислительную смесь различных образцов: кривая 0 - холостая проба, 1 - 1 мкл тролокса; 2 - 0,5 мкл №13; 3 - 1 мкл №1, 4 - 2 мкл №1; 5 - 20 мкл №2; 6 - 2 мкл №10а, 7 - 2 мкл №10б

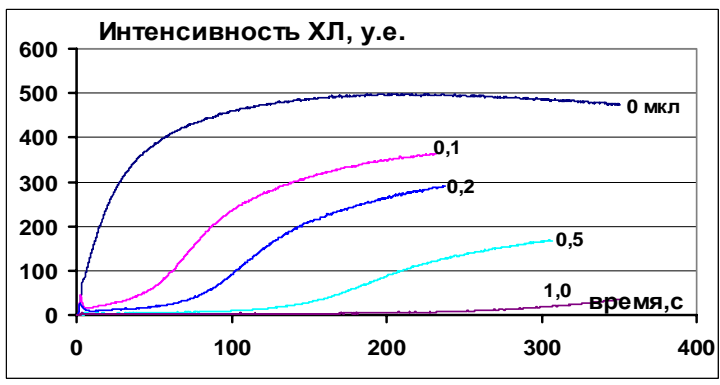

Рис. 3. Динамика интенсивности ХЛ при добавлении в окислительную смесь различных доз образца №5

Вид алое A. pillansii (синоним Aloe dichotoma subsp. pillansii (L.Guthrie) Zonn.) практически не изучен (рис. 4, http://www.lapshin.org/succulent/o-al-pil.htm). Его родиной является Южная Африка: пустыни Анголы, пустыня Намиб, аридные районы плоскогорья Намакваленд. A. pillansii предпочитает плоские каменистые вершины невысоких холмов. Представляет собой небольшие, сильно разветвленные деревья (до 6-9 м, при толщине ствола до метра). А. пилланса тяготеет к прямостоячему древесному типу (стройное, обычно менее разветвленное), А. дихотома - густой кустарник. В молодом возрасте виды не различаются. Ветви беловато-серые, голые, гладкие, блестящие, на концах несут розеток очень сочных листьев. Листья линейно-ланцетные, 25-35 см длиной, 5-6 см шириной, голубовато-зеленые, шиповатые по краям. Соцветия ветвистые, прямостоячие, цветки трубчатые, желтые.

Компоненты второй группы образцов экстрактов (№1, 2, 7, 11, 12) подавляют ХЛ несколько подругому (кривые 3, 4, 5 рис. 2): очень плохо выраженный малый латентный период даже при высоких дозах (кривая 5 для 20 мкл образца №2), медленное развитие свечения и значительное уменьшение амплитуды. У этих экстрактов сравнительно малые значения АОА, измеренные амперометрией, свидетельствующие о невысоком содержании в листьях этих видов активных низкомолекулярных антиоксидантов, но присутствуют компоненты, вероятней всего, белковые или ферментные, которые сильно подавляют амплитуду ХЛ, но не окисляются на аноде амперометрического детектора. Для образца №2 (A. vera) это полисахариды, как показано в [15, 16].

Для самого популярного вида A. arborescens (№1) амперометрическим методом получены высокие значения АОА, что, по-видимому, обусловлено присутствием в нем достаточного количества фенольных соединений (элоэнин, алоин, алоэ-эмодин и др.), органических кислот и некоторых аминокислот [10-12], однако значения AOA, измеренные хемилюминесценцией, оказались на порядок меньше. Как показано авторами в [11], сок A. arborescens вызывает инактивацию молекул $\mathrm{H}_{2} \mathrm{O}_{2}$ за счет присутствия в нем ряда ферментов (каталаза, пероксидаза) и ионов тяжелых металлов, потенцирующих процесс разложения $\mathrm{H}_{2} \mathrm{O}_{2}$. Кроме того, полисахаридные комплексы в составе сока

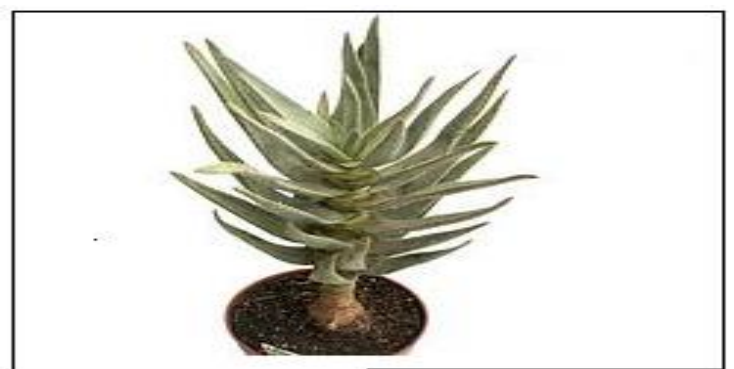

Рис. 4. Внешний вид образца №5 A.pillansii. (http://www.lapshin.org/succulent/o-al-pil.htm)
A. arborescens хелатируют ионы $\mathrm{Fe}^{2+}$ и связывают ионы тяжелых металлов [10]. Поэтому эти компоненты сока или экстракта и не дают развиться нормальному ХЛ свечению, связывая перекись водорода и $\mathrm{Fe}^{2+}$ из гемоглобина, присутствующие в хемилюминесцентной окислительной смеси «(Hb) - $\left(\mathrm{H}_{2} \mathrm{O}_{2}\right)-$ люминол», занижая значения латентного периода, определяющего AОА. Вероятно, что это характерно и для других видов, имеющих низкие значения АОА по ХЛ при высоких АОА по амперометрии (№6, 7, 11, 12).

На рисунке 5 приведены сравнительные диаграммы для 15 образцов экстрактов из таблицы 1. 

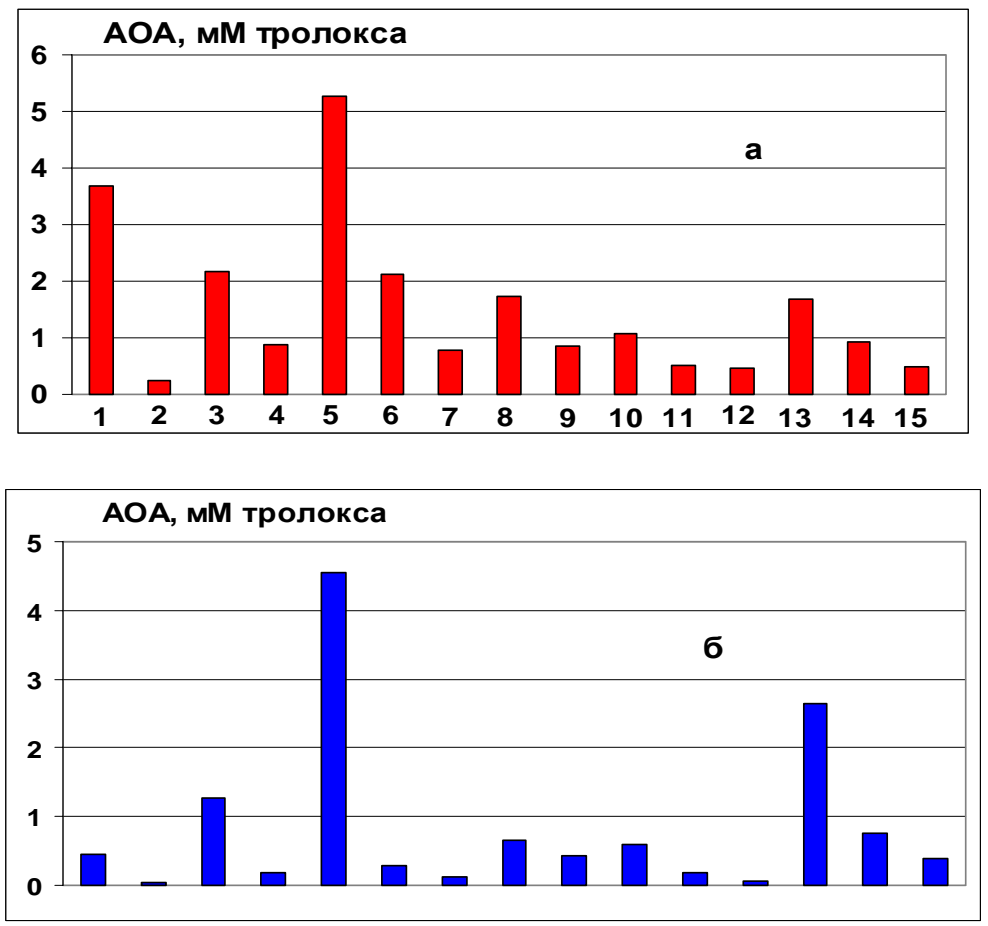

Рис. 5. Диаграммы АОА образцов экстрактов Алое из таблицы 1 для двух методов измерения: амперометрия (а) и хемилюминесценция (б)

Бесспорным «аутсайдером» оказался экстракт A. pillansii (№5). Оба метода показали для него почти одинаковые высокие значения АОА, а компоненты, мешающие развитию ХЛ, как в A. arborescens, повидимому, присутствуют в незначительном количестве. Для образца №3 (A. spinosissima) AOA по амперометрии оказалась почти в два раза выше, чем по ХЛ, а для образца №13 (A. broomii) наоборот. Безусловно, желательно изучить химический состав соков или экстрактов этих видов Алое, чтобы понять, за счет чего это происходит.

Для расширения возможности использования указанных выше видов Алое, как источников биологически активных соединений, необходимо проведение дополнительных исследований соков и экстрактов этих растений на предмет изучения их химического состава, а также антибактериальных, противомикробных, фиторегулирующих и других свойств компонентов этих растений. Возможно, они окажутся не менее перспективными, чем известные виды Алое, и для использования их в медицине.

\section{Выводы}

Проведены измерения АОА спиртовых экстрактов из листьев 15 видов Алое амперометрическим и хемилюминесцентным методами. Сравнение результатов измерений выявило невысокую корреляцию результатов для этих методов ( $\mathrm{r}=0,704$, с уровнем значимости $\leq 0,001)$ у большинства видов Алое, что объясняется особенностями выбранной хемилюминесцентной окислительной модели, не пригодной для этих видов алое. Поэтому более приемлемым для них можно считать амперометрический метод. Среди изученных образцов выявлен наиболее активный с точки зрения АОА представитель рода Аlое A. pillansii, имеющий высокие значения АОА, полученные обоими методами. Достаточно активными, кроме него и A. arborescens, оказались также A. broomii u A. spinosissima. Они могут оказаться не менее перспективными источниками биологически активных соединений, чем использующиеся в настоящее время виды Алое.

\section{Список литературы}

1. Лекарственное растительное сырье. Фармакогнозия / ред. Г.П. Яковлев, К.Ф. Блинова. СПб., 2004. 765 с.

2. Сажина Н.Н., Лапшин П.В., Загоскина Н.В., Короткова Е.И., Мисин В.М. Сравнительный анализ антиоксидантной активности соков Каланхое // Химия растительного сырья. 2013. №3. С. 113-119. 
3. Яшин А.Я., Яшин Я.И., Черноусова Н.И., Пахомов В.П. Экспрессный электрохимический метод определения антиоксидантной активности пищевых продуктов // Пиво и напитки. 2004. №6. С. 44-46.

4. Яшин А.Я., Рыжнев В.Ю., Яшин Я.И., Черноусова Н.И. Природные антиоксиданты. Содержание в пищевых продуктах и их влияние на здоровье и старение человека. М., 2009. С. 124.

5. Федина П.А., Яшин А.Я., Черноусова Н.И. Определение антиоксидантов в продуктах растительного происхождения амперометрическим методом // Химия растительного сырья. 2010. №2. С. 91-97.

6. Yashin Y.I., Nemzer B.V., Ryzhnev V.Y., Yashin A.Y., Chernousova N.I., Fedina P.A. Creation of a Databank for content of antioxidants in food products by an amperometric method // Molecules. 2010. Vol. 15. Pp. 7450-7466.

7. Семенова Л.В., Ямпольский Ю.В. Лекарственные экзотические растения. Вып. 1. СПб., 2003. 125 с.

8. Меньщикова Е.Б., Ланкин В.З., Зенков Н.К., Бондарь И.А., Круговых Н.Ф., Труфакин В.А. Окислительный стресс. Прооксиданты и антиоксиданты. М., 2006. 556 с.

9. Costa P., Gonçalves S., Valentão P., Andrade P. B., Romano A. Accumulation of phenolic compounds in in vitro cultures and wild plants of Lavandula viridis L'Hér and their antioxidant and anti-cholinesterase potential // Food and Chemical Toxicology. 2003. Vol. 57. Pp. 69-74.

10. Оленников Д.Н., Зилфикаров И.Н., Ибрагимов Т.А. Исследование химического состава алое древовидного (Aloe arborescens Mill.) // Химия растительного сырья. 2010. №3. С. 77-82.

11. Оленников Д.Н., Зилфикаров И.Н., Ибрагимов Т.А., Торопова А.А., Танхаева Л.М. Химический состав состав сока алое древовидного (Aloe arborescens Mill.) и его антиоксидантная активность (in vitro) // Химия растительного сырья. 2010. №3. С. 83-90.

12. Оленников Д.Н., Рохин А.В., Зилфикаров И.Н. Методика определения содержания фенольных соединений в Aloe arborescens // Химия природных соединений. 2008. №6. С. 578-580.

13. Di Luccia B., Manzo N., Vivo M. at al. A biochemical and cellular approach to explore the antiproliferative and prodifferentiative activity of Aloe arborescens leaf extract // Phytother Res. 2013. Vol. 27. N12. Pp. 1819-1828.

14. Рюшина В.А., Габрук Н.Г., Шутеева Т.А. Идентификация биологически активных компонентов Aloe arborescens Miller // Научные ведомости БелГУ. Сер. Естественные науки. 2010. Т. 3 (74), вып. 10. С. $93-96$.

15. Kaithwas G., Singh P., Bhatia D. Evaluation of in vitro and in vivo antioxidant potential of polysaccharides from Aloe vera (Aloe barbadensis Miller) gel // Drug ChemToxicol. 2014. Vol. 37. N2. Pp. 135-143.

16. Zhong J., Huang Y., Ding W., Wu X., Wan J., Luo, Chemical constituents of Aloe barbadensis Miller and their inhibitory effects on phosphodiesterase-4D // Fitoterapia. 2013. Vol. 91. Pp. 159-165.

17. Chen W., Van Wyk Ben-Erik, Vermaak I., Viljoen A.M. Cape aloes - A review of the phytochemistry, pharmacology and commercialisation of Aloe ferox // Phytochemistry Letters. 2012. Vol. 5. N1. Pp. 1-12.

18. Induli M., Cheloti M., Wasuna A., Wekesa I., Wanjohi J.M., Byamukama R., Heydenrich M., Makayoto M., Yenesew A. Naphthoquinones from the roots of Aloe secundiflora // Phytochemistry Letters. 2012. Vol. 5. N3. Pp. 506-509.

19. Ndhlala A.R., Amoo S.O., Stafford G.I., Finnie J.F., Van Staden J. Antimicrobial, anti-inflammatory and mutagenic investigation of the South African tree aloe (Aloe barberae) // Journal of Ethnopharmacology. 2009. Vol. 124. N3. Pp. 404-408.

20. Zapata P.J., Navarro D., Guillen F., Castillo S., Martinez-Romero D., Valero D., Serrano M. Characterisation of gels from different Aloe spp. as antifungal treatment: Potential crops for industrial applications // Industrial Crops and Products. 2013. Vol. 42. Pp. 223-230.

21. Gihan O.M.E., Achyut A., Sammer Y., Hafizur R., Asaad K., Hala O., Hoong-Kun F., Humaira J., Iqbal C., Sakina Y. Phytochemistry and antiglycation activity of Aloe sinkatana Reynolds // Phytochemistry Letters. 2012. Vol. 5. N4. Pp. 725-728.

22. Запрометов М.Н. Основы биохимии фенольных соединений. М., 1974. 216 с.

23. Яшин А.Я. Инжекционно-проточная система с амперометрическим детектором для селективного определения антиоксидантов в пищевых продуктах и напитках // Российский химический журнал. 2008. T. LII. №2. C. $130-135$.

24. Peyrat-Maillard M.N, Bonnely S., Berset C. Determination of the antioxidant activity of phenolic compoundsby coulometric detection // Talanta. 2000. Vol. 51. Pp. 709-715.

25. Бирюков В.В. Особенности определения концентрации антиоксидантов амперометрическим методом // Химия растительного сырья. 2013. №3. С. 169-172.

26. Теселкин Ю.О., Бабенкова И.В., Любицкий О.Б. и др. Ингибирование сывороточными антиоксидантами окисления люминола в присутствии гемоглобина и пероксида водорода // Вопросы медицинской химии. 1998. T. 44. №1. C. 70-76.

27. Дерффель К. Статистика в аналитической химии. М., 1994. 268 с.

Поступило в редакцию 31 октября 2014 г. 
Sazhina N.N. ${ }^{1 *}$, Lapshin P.V. ${ }^{2}$, Zagoskina N.V. ${ }^{2}$, Misin V.M. ${ }^{l}$ COMPARATIVE STUDY OF ANTIOXIDATE PROPERTIES FOR VARIOUS ALOE KINDS EXTRACTS

${ }^{1}$ Institute of Biochemical Physics, Russian Academy of Sciences N.M. Emanuel, ul. Kosygina, 4, Moscow, 119334 (Russia),e-mail: Natnik48s@yandex.ru

${ }^{2}$ Institute of Plant Physiology. K.A. Timiryazev Academy of Sciences, ul. Botanicheskaja, 35, Moscow, 127276 (Russia)

Now the special attention to studying of antioxidant activity of various herbs is given for the purpose of search among them the most active sources of biologically active components. In this work for this purpose the comparative analysis of measurement results of the total antioxidant activity (AOA) for spirit extracts of 15 different kinds of Aloe (Aloe L.) is carried out by ammetric and chemiluminescence methods. The considerable difference between AOA values, received by these methods for some Aloe kinds is noted. Among the studied samples, except A.arborescens, some active Aloe sorts are revealed: A. pillansii, A. broomii and A.spinosissima. They can also appear perspective sources of biologically active components.

Keywords: antioxidant, ammetric and chemiluminescence methods, polyphenols, Aloe.

\section{References}

1. Lekarstvennoe rastitel'noe syr'e. Farmakognozija. [Medicinal herbs. Pharmacognosy], ed. G.P. Jakovlev, K.F. Blinova, Saint Petersburg, 2004, 765 p. (in Russ.).

2. Sazhina N.N., Lapshin P.V., Zagoskina N.V., Korotkova E.I., Misin V.M. Himija rastitel'nogo syr'ja, 2013, no. 3, pp. 113-119. (in Russ.).

3. Jashin A.Ja., Jashin Ja.I., Chernousova N.I., Pahomov V.P. Pivo i napitki, 2004, no. 6, pp. 44-46. (in Russ.).

4. Jashin A.Ja., Ryzhnev V.Ju., Jashin Ja.I., Chernousova N.I. Prirodnye antioksidanty. Soderzhanie v pishhevyh produktah $i$ ih vlijanie na zdorov'e, $i$ starenie cheloveka. [Natural antioxidants. The content in foods and their impact on health and human aging]. Moscow, 2009, p. 124. (in Russ.).

5. Fedina P.A., Jashin A.Ja., Chernousova N.I. Himija rastitel'nogo syr'ja, 2010, no. 2, pp. 91-97. (in Russ.).

6. Yashin Y.I., Nemzer B.V., Ryzhnev V.Y., Yashin A.Y., Chernousova N.I., Fedina P.A. Molecules, 2010, Vol. 15, Pp. 7450-7466.

7. Semenova L.V., Jampol'skij Ju.V. Lekarstvennye jekzoticheskie rastenija. [Medicinal exotic plants]. Issue. 1, Saint Petersburg, 2003, 125 p. (in Russ.).

8. Men'shhikova E.B., Lankin V.Z., Zenkov N.K., Bondar' I.A., Krugovyh N.F., Trufakin V.A. Okislitel'nyj stress. Prooksidanty i antioksidanty. [Okislitel'nyj stress. Prooksidanty i antioksidanty]. Moscow, 2006, 556 p. (in Russ.).

9. Costa P., Gonçalves S., Valentão P., Andrade P.B., Romano A. Food and Chemical Toxicology, 2003, vol. 57, pp. 69-74.

10. Olennikov D.N., Zilfikarov I.N., Ibragimov T.A. Himija rastitel'nogo syr'ja, 2010, no. 3, pp. 77-82. (in Russ.).

11. Olennikov D.N., Zilfikarov I.N., Ibragimov T.A., Toropova A.A., Tanhaeva L.M. Himija rastitel'nogo syr'ja, 2010, no. 3, pp. 83-90. (in Russ.).

12. Olennikov D.N., Rohin A.V., Zilfikarov I.N. Himija prirodnyh soedinenij, 2008, no. 6, pp. 578-580. (in Russ.).

13. Di Luccia B., Manzo N., Vivo M. at al. Phytother Res. 2013, vol. 27, no. 12, pp. 1819-1828.

14. Rjushina V.A., Gabruk N.G., Shuteeva T.A. Nauchnye vedomosti BelGU. Ser. Estestvennye nauki. 2010, vol. 3 (74), no. 10, pp. 93-96. (in Russ.).

15. Kaithwas G., Singh P., Bhatia D. Drug ChemToxicol. 2014, vol. 37, no. 2, pp. 135-143.

16. Zhong J., Huang Y., Ding W., Wu X., Wan J. Fitoterapia, 2013, vol. 91, pp. 159-165.

17. Chen W., Van Wyk Ben-Erik, Vermaak I., Viljoen A.M. Phytochemistry Letters, 2012, vol. 5, no. 1, pp. 1-12.

18. Induli M., Cheloti M., Wasuna A., Wekesa I., Wanjohi J.M., Byamukama R., Heydenrich M., Makayoto M., Yenesew A. Phytochemistry Letters. 2012, vol. 5, no. 3, pp. 506-509.

19. Ndhlala A.R., Amoo S.O., Stafford G.I., Finnie J.F., Van Staden J. Journal of Ethnopharmacology, 2009, vol. 124, no. 3, pp. 404-408.

20. Zapata P.J., Navarro D., Guillen F., Castillo S., Martinez-Romero D., Valero D., Serrano M. Industrial Crops and Products, 2013, vol. 42, pp. 223-230.

21. Gihan O.M.E., Achyut A., Sammer Y., Hafizur R., Asaad K., Hala O., Hoong-Kun F., Humaira J., Iqbal C., Sakina Y. Phytochemistry Letters, 2012, vol. 5, no. 4, pp. 725-728.

22. Zaprometov M.N. Osnovy biohimii fenol'nyh soedinenij. [Fundamentals of Biochemistry of phenolic compounds]. Moscow, 1974, 216 p. (in Russ.).

23. Jashin A.Ja. Rossijskij himicheskij zhurnal. 2008, vol. LII, no. 2, pp. 130-135. (in Russ.).

24. Peyrat-Maillard M.N., Bonnely S., Berset C. Talanta. 2000, vol. 51, pp. 709-715.

25. Birjukov V.V. Himija rastitel'nogo syr'ja. 2013, no. 3, pp. 169-172. (in Russ.).

26. Teselkin Ju.O., Babenkova I.V., Ljubickij O.B. i dr. Voprosy medicinskoj himii, 1998, vol. 44, no. 1, pp. 70-76. (in Russ.).

27. Derffel' K. Statistika v analiticheskoj himii. [Statistics in analytical chemistry]. Moscow, 1994, 268 p. (in Russ.).

Received October 31, 2014

Revised April 30, 2015

\footnotetext{
* Corresponding author.
} 